ISBN 978-81-933894-1-6

International Conference on Arts, Social Sciences, History And Interdisciplinary Studies

(ASSHIS-2017)

Kyoto (Japan), April. 20-21,2017

\title{
Chinese traditional elements and Chinese logo
}

\author{
DongShuo Zhu \\ College of Arts, Renmin University of China
}

\begin{abstract}
Chinese elements are important for the design of Chinese logos. The development of Chinese logos is introduced in the paper,and the traditional elements in Chinese culture are explained,also,common Chinese elements in logos are analyzed.Moreover, the advantages and possible problem are shown.
\end{abstract}

Keywords: traditional elements, Chinese logo, design, patterns, culture.

\section{Introduction}

China is a country with a long history and many nationalities.In the development of the county and in the transition of the nations numerous art compositions were created.These pieces are components in Chinese culture , and are Chinese traditional elements with the feature of China.

There are various sources for Chinese traditional elements.Some of them are from folklore or folk literature,some from Chinese mythology,and some from religions. There are also many other sources for these elements.

During thousands of years in Chinese history,China changed a great deal.However, the tradition and culture of China from ancient times still affect the life in the country today. The signification for most Chinese elements has not changed at all.A delineation expressing good wishes a thousand years ago in China has the totally the same meaning currently.This is the foundation on using Chinese elements in logo.

As a matter of fact,using Chinese elements in logo is an effect way to enable a logo to bear the background of Chinese culture.Moreover,it is a way to indicate the nationality of an organization using the logo. Putting Chinese traditional elements into logo design will be a useful way to display the style for a China brand or organization.The Chinese elements used in logo are increasing rapidly with the developing of multiple marketing.These Chinese elements include Chinese characters, writing brushes,penmanship,religious symbols, auspicious totems, etc.

\section{The developing of Chinese logo}

In China,totemism was the cause of the earliest logos.For totem,it can be traced to the design of emblem in ancient times.Chinese logo originated from the seal ,which first appeared in the end of Chunqiu period,being popular in QinHan and Wei-Jin dynasties,disappeared in Tang dynasty.The function of the seal was a symbol when people exchange commodities.It was the first logo in China.During the exchange of commodities, people use clay to fix ropes.Before the clay was totally dry,a symbol to represent a store was pressed on it,the function of which was to protect their prestige and to make sure that their commodities were not untied in the process of selling.

In Han dynasty,logos began to appear on bronze ware and lacquerwork.This period was peaceful and prosperous, while purchases and sales were very frequent.Bronze ware and lacquerwork were produced not only by workshop run by the government,but also by individual ones. And these workshops might also print their symbols on their products to make their goods distinguishable from those of their rivals.Dong's workshop and Yan's workshop were famous during this period.

In Tang dynasty,an anti-counterfeiting mark appeared in China, which was named the signet of hidden pattern.In Song dynasty,there were many different forms of logos.For example,the most famous one was a rabbit 
embracing a needle with words 'recognizing the rabbit in front of door'. This logo was also the earliest one ever found on a parcel in China. Moreover,the form of the combination of pictures and characters in this logo was an innovation for logo design in our country. Then many similar logos, which could represent their own commodities and make a best wishes to their customers, appeared.For example,drugstore would like to use the god of longevity,jewelry store would like to use Ruyi(an S-shaped ornamental object made of jade,formerly a symbol of good luck) and etc.However,until Yuan and Ming period,logo did not change much in China.In 1840 A.D., the period of the first Opium War, it began to change in logo design. Since foreigners wanted to sell their goods, they used Chinese traditional patterns in logo, which could help them to obtain higher profit.Today,logo design is still staying at exploratory stage in China.Just as Jun Gao suggested, 'For now, the advertising is still in a pedantic period,and good works are rare.We had indiscriminately imitated overseas experience, and it was found useless.Old rules won't work,and new pattern still cannot be found...The approaches we used previously are under suspicion and reconsideration, but we do not know where we can find the new methods, which is the current situation for advertising and idea creating in China.There is a phenomenon in advertising,we do not trust ourselves,considering ours not the authentic modern products, even scholars also have this idea.This kind of lack of confidence led to copying overseas pattern,but we cannot grasp their spirit,and we do not use the things worshiped by foreigners in many occasions...we adore overseas things, and we ignore the things of our own."Paying attention to our own tradition, digging our own national spirit and using them into our design are of great urgency.

\section{The traditional visual element in China}

\subsection{Various Chinese Traditional Visual Elements}

China has a long cultural history.From the earliest cave painting to all kinds of novel art today,we have accumulated a large number of visual elements in art, which can be used in graphic design and logo design.The representative ones include:Chinese Calligraphy,Chinese characters, Chinese seal cutting,endless knot,traditional Chinese painting,wall painting,auspicious grain(dragon and phoenix pattern,taotie design,ruyi design,ray pattern,fret),Chinese brocade and embroidery arts,auspicious cloud pattern,paper-cut,types of facial make-up in beijing opera,etc.

3.2The difference between the visual elements in China and the Occidental ones.

The crystallized ideas and essences with thousands of years history in China are included in the traditional visual elements.We can utilize these elements in logo design. These visual elements can effectively reflect our Chinese ideas and cultural inheritance.People in China and those in the Occident have totally different thinking modes and ideas.In the Occident,since the period of Plato,they regard"unique style"as their outstanding feature, and value figurativeness, liveliness and novelty."while integral Consciousness"is emphasized in China.Meanwhile, the Chinese believe in naturalness and the theory that "man is an integral part of nature"the idea from their ancestors. We can find out the differences between these two art forms in western oil painting and traditional Chinese painting.The western oil paintings are usually a part of landscape,however,the traditional Chinese paintings are always the panorama of landscape,pursuing the state of ordered harmony of personages and scenery.

For logos, Chinese design and western design are also quite different.As shown below, it will be very obvious when there are any Oriental elements in logo design.Chinese ink painting and Chinese Calligraphy are valuable Chinese traditional elements in logo design.To express the magnolia flower Chinese ink and design were used in the following design,which enables people to feel simple and elegant,highlighting the style pursued by this restaurant.In addition, using the form of Chinese Calligraphy to express the three characters can make the logo more attractive.There are only two colors in this logo,and the colors are integrated to each other, which bearing harmonious beauty.(Fig.1)And another picture is a western logo,which also uses the color of red and black, but the match up between these two colors are quite contrasty, revealing the characteristic of foreign logo design ,pursuing their own individualization.(Fig.2)

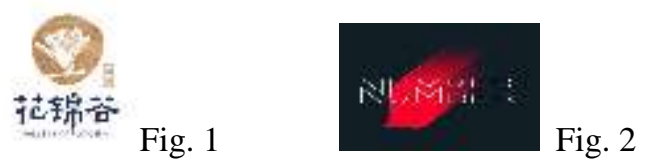




\section{Common Chinese elements in logo design}

\subsection{Chinese Character, Chinese calligraphy, Pen and Ink}

The basis of Chinese characters is carved symbols.Passing millenniums the figures and pictographs in the period of oracle bone gradually evolved to the Chinese ideograph system, integrating sound,meaning and shape.The most prominent feature for Chinese characters comparing with foreign text is that they are pictographic, hence the argument that painting and calligraphy are homologous.Primitive men wanted to express themselves and they began to produce pictures which were the earliest Chinese characters.Today,we call them pictographic characters .Before Xia dynasty,all of the carved symbols, bone sculpture,and zhu wen are the graphic text and hieroglyphic characters. The oracle bone script which appeared in Yin dynasty is still one kind of hieroglyphic characters.Until Qin dynasty,Si Li began to process a uniform script.Only when Chinese characters evolved to the characters which we named Xiao zhuan now the trace of hieroglyphic characters disappeared. Chinese characters which we frequently use now include seal character,regular script,running hand,Yan,and Xing.Chinese characters as symbols to record language in ancient China gradually evolved to an important standard which can display Chinese aesthetic culture and spiritual connotation.Chinese characters gradually developed to many interrelated art forms such as typeface,Chinese calligraphy,seal cutting,and stamp.According to Sanmu Deng,"Chinese characters were derived from hieroglyphs, then it evolved to the six categories of Chinese characters, which not only can be used as characters but also have simplified forms.Meanwhile,there is still artistic value in it.....Chinese character is a base for every kind of art in China."As a common art carrier,Chinese character influences the aesthetic psychology,aesthetical standard,and state of aesthetic judgment for the Chinese.

When we use Chinese character in logo design,we will frequently bound it up with pen and ink and Chinese Calligraphy.Chinese Calligraphy can reflect Chinese own artistic characteristic and spiritual connotation of Chinese art. Xun Lu suggested that Chinese character "has three kinds of beauty:firstly,the beauty of meaning can touch heart;secondly,the beauty in sound can please ear;thirdly,the beauty of form is pleasant to eye.'The third beauty, or the beauty of form, is that using Chinese Calligraphy to display its attraction.Just like the Chinese old saying:the writing is like the personality.

We cannot do without writing brush and ink to display Chinese Calligraphy, which are also important elements in logo design. Writing brush and ink mean the technique of writing and the method of use of ink. The meaning of writing technique is the maneuver of writing brush,wihch is decided by the point of writing brush and the strength in writing. The results of writing are various. "The force in writing can carry the tripod", "write like an angel"are the phrases to describe the strength and elegance in writing. The methods of the use of ink include dark,light,dry,wet, thirsty and swollen.The method of the use of ink is very important in both Chinese painting and Chinese Calligraphy.The ancients would like to use"regard one's ink as if it were gold"to emphasize the importance of the ink.By using the method of dark,wet,dry,and light in ink and water one can express different sequence in a painting,which can enable the painter to give expression to their artistic conceptions. Talking about pen and ink,it is a necessity to emphasize the art form of the style of hollow stroke,which is an effect in Chinese Calligraphy by the special handling of writing brush.The advantage of the style of calligraphy characterized by hollow stroke is its originality and non-repeatability.It is unique for every stroke, and the visual impact brought by this art form cannot be replaced by other approaches.As the following drawing shown(Fig.3),the logo of the bank of China designed by Daiqiang Jin is full of Chinese characteristics.In this logo,the figure is the image of a copper coin in ancient China.On the one hand,it can fully match with the theme of bank,on the other hand,it may conform to the aesthetic ideology "outwardly gentle but inwardly stern". Under the image are Chinese character for "Bank of China"hollow stroke and the choosing of the style of calligraphy can make the Chinese characteristics more distinctive.The right design (Fig.4)is a logo for a foreign bank,and it is clearly different from the Chinese one.The logo on the left is red, which is usually to represent a joyous feeling in China,and the right one is blue, showing the sagacity.

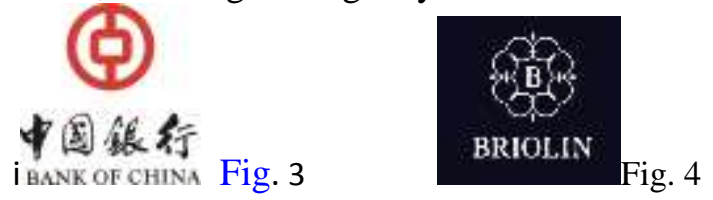




\subsection{Paper-Cut,Endless Knot,the Great Ultimate,the Ruyi}

Chinese paper-cut is one kind of folk art produced by using scissors or graver to cut figures out on paper,which can generally be used to decorate people's life or in folk activities.Paper-cut is a form for people to express their aesthetic taste. The kind of art form can be traced to the $11^{\text {th }}$ century BC in Shang and Zhou dynasties.In 2006,paper-cut was listed in the National Intangible Cultural Heritage in China.In 2009, it has been named Masterpieces of the Oral and Intangible Heritage of Humanity.The artistic modeling for paper-cut originated from primitive rock painting and ancient painted pottery.By means of artistic expression of carving, Chinese paper cutting art creates the works which have many special features like exaggeration and personification. The logos applied the art form of paper-cut may enable people to feel a new appearance .The logo which is shown below (Fig.5)uses not only the element of paper-cut but also endless knot,ruyi,and calligraphy.People can feel the full of the antique appeal and beauty from this logo.The logo which is shown below (Fig.6) is designed for the hall of Poland in Shanghai Expo in 2010.The effect of Chinese paper-cut and the figure which can represent the feature of Poland are matching in this logo, which can stand out by its clever design.

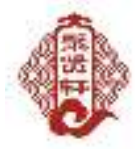

Fig. 5

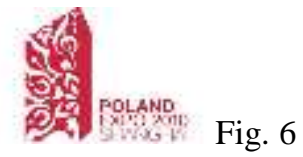

Endless knot,which was the $8^{\text {th }}$ one in Ashtamangala,also called lucky knot.It means coming again and again and permanence in Buddhism.People use lucky knot to express good wishes to their family and offspring.Chinese knot is evolved from it.This Chinese element is accepted by people and is used in logo design.The most famous logo with endless knot pattern is probably the logo of China Unicom(Fig.7).Using endless knot,this logo displays their business philosophy about extending in all directions and unimpeded signal.Moreover,endless knot can also express future expectation for this corporation by its connotation about circle of life.Important information such as enterprise feature,corporate culture can also be expressed by this logo.

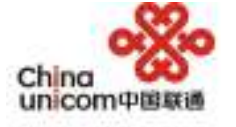

Fig. 7

Tai Ji is significant in Chinese cultural history.It was used to express the origin of the world in ancient Chinese philosophy.It means ultimate source for all the things in the universe in Taoism. Taiji appeared later than eight diagrams,but it is similar to eight diagrams.Taiji element is used in the following logos(Fig.8,Fig.9,Fig.10). These logos involve wide range of business,such as:building industry,tea industry and technology industry.But we do not feel abrupt in all of these three logos.From these vivid evidences, we can find out that the using of the elements can not be limited to industry.Actually,all of these logos are not typically used Taiji element in design.The most typical one must be the South Korean flag.Many Chinese traditional elements are used and developed by other Asia countries.In Japanese design the elements of Chinese Calligraphy and Chinese pen and ink are very common. Chinese designers have to shoulder heavy responsibility to find ways to develop the Chinese elements in Chinese design.

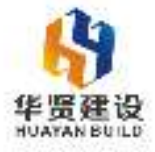

Fig.8

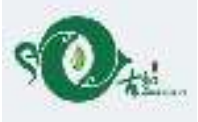

Fig. 9

Fig. 8

In ancient China,people used Ruyi to relieve itching as a tool.It appeared in Warring States Period,In Qing Dynasty,being a symbol of good luck, Ruyi used extensively in the royal court, for example, when an emperor ascended the throne,or received foreign guests.Ruyi was also a folk article in social activities,furnishing,etc.Now,Ruyi is still a widely known symbol of auspiciousness.In logo design,Ruyi is also widely used,and the pattern can be very changeable.For example, the following are logos of two different kinds of businesses(Fig.11,Fig.12), in which Ruyi element was used,and the element in these logos are harmonious. Both of them extract the propitious meaning in Ruyi. 


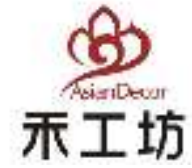

Fig. 9

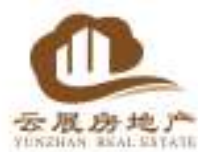

Fig. 10

\subsection{Other kinds of Patterns in Chinese Traditional Culture}

Chinese graphic arts have a long history, from the ancient rock painting to the gluttonous graphs on bronze ware in Shang Dynasty,from tadpole character and plum blossom seal character in the Spring and Autumn period and Warring State period to the phoenix pattern in Han Dynasty,and rosette design in Tang Dynasty,etc.These patterns recorded the developing and evolving in Chinese traditional pattern art.It expresses the Chinese aesthetic psychology.The sedimentation of these traditional decoration patterns and figures became a rounded art system which contain our unique national style and became an important part in our country's design element.There are various Chinese traditional patterns which can be used in design as the elements,even including facial makeup in Beijing Opera.In the following restaurant logos (Fig.13,Fig.14)the facial makeup in Beijing Opera was used as an element in the design.Both logos show the traditional Chinese feature.As mentioned above,red means auspicious in logo design,and it can also enable people to feel warm.Actually,restaurant is a place to provide warmth and comfort.This kind of design is likely to attract more people to come.

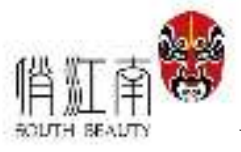

Fig. 11 12

\section{The Problems for the use of Chinese Traditional Elements in logo Design}

Chinese companies and organizations would like to use Chinese traditional art elements into their logo design,but not every country and nation can accept all of these logos and elements.Countries and nations may have differences within the background of life and culture,which may cause difference in understanding for the same element.If Chinese designers overlook this problem when they use Chinese traditional elements in their design, it may lead to negative effects,and these businesses and organizations may even be rejected by other countries and nations.

\subsection{The Problem Caused by the Language Barriers}

The picture in the lower left is the logo of a Chinese Company.Foreigners cannot understand the meaning of this logo,as it is only a simple character.It may cause language barrier problem to use Chinese Calligraphy and character in logo design.some logos may use Chinese phonetic symbols, such as the logo in the following (Fig.15,Fig.16),but it still may have negative effect for recognition.Because Chinese phonetic symbols cannot enable foreign people to understand the meaning for the character.Sometimes, we only consider innovation and concordance for color when we design a logo.However,we should consider a more important factor internationalization,because we live in the global village, and we should adjust ourselves and our ideas to this new world.Of course, many logos may only be used in China, but we should understand that there are many foreigners who live in our country.So we need still to consider this factor.Otherwise we may lose our clients. When we design a logo,no matter for an activity or a brand,we should try to attract more customers.

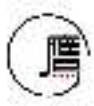

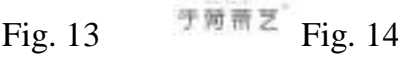

\subsection{Ambiguity Caused by Cultural Connotation Differences.}

China and the Occident have different cultural roots,and they have various cultural connotation differences.In China,people give priority to harmony,and they pursue the harmonious relationship between people and people,people and society,people and nature.Comparing with China,western people pay more attention on rationality,and they want to know and transform the world,making it suitable for human beings. These two different peoples may have totally different understanding when they face the same thing,given the cultural 
divergence.For example,the meaning of dragon is quite different for Chinese people and western people.In Chinese culture dragon means elegance,dignity.For example,in ancient China,prince was called the son of dragon.For western people,dragon means evil.In the western mythology,it is another name for Satan who is antagonistic to god.From the attitude to dragon,we can see the differences between Chinese and western culture.For the following logos(Fig.17,Fig.18,Fig.19), the one in the middle is obviously different from the other two.It is more difficult for foreign customers to understand.This question may frequently happen in Chinese logo design, and we should try to find a strategy to solve it before we begin to design.

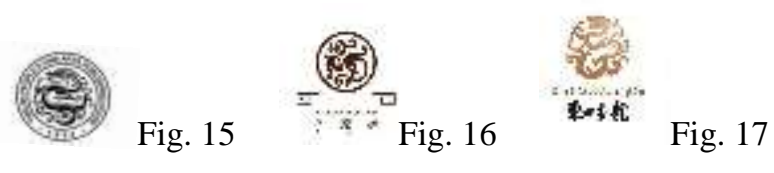

\subsection{The Differences Between China and the Occident Logo Design in the Using of Color}

As mentioned above,the concept in China and the Occident has obviously difference.The using of color is another .Color is an important factor in logo design.So, designers have to consider what color should be used in logo,and can be accepted by both Chinese and western people.We may take white as an example. In China,white may have negative meaning, which may link to things concerning bad luck.But it is not the same in English,where white means pure,happiness, such as 'white day','white city','white lie', etc.There are many other examples.For instance black may mean evil in western culture,it may mean serious and fair in China.In Beijing Opera,facial makeup are black for Bao Zheng and Li Kui, both of whom are positive characters.More and more designers try to avoid negative effect when they need to confront this problem. The following logo is the logo for the Beijing 2008 Olympic Games, called“Dancing Beijing", and the main color in the logo is red.Actually,red is an auspicious color in Chinese culture.People in China would like to wear red clothes on wedding, and there is a color called Chinese red.

\subsection{Connotation is Difficult to Understand when it is too Deep}

Besides some difficult typefaces such as seal character,there are some Chinese elements in a logo,which are too hard to understand.Taiji is a simple element for people to understand,and there is another element named eight diagram,while few people can understand it.The left one of the following logos is the South Korean flag(Fig.20), and the meaning of the logo is not easy to understand.The logo of Phoenix Satellite television is quite different.There are two elements in this logo,phoenix and Taiji,and the Taiji means circle of life .The logo of Phoenix Satellite television(Fig.21) is easier to understand.Therefore we should use the elements which can be understood by the majority of people,instead of the unfamiliar elements.

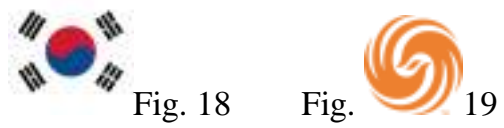

\section{The Advantage for Chinese Traditional Elements}

China is still a mystery country for many western people. The long history and the vast territory still attract more and more foreigners' attention. When we use the Chinese traditional elements in logo design,such as dragon pattern,phoenix pattern or Chinese Calligraphy,foreigners may possibly be attracted by these exotic logos,and it can be easier to get the identifiability and memorability, which are very important for logo design. When a logo has Chinese traditional elements that can be accepted by foreigners the design can be outstanding in numerous pieces.The following logo 'Dancing Beijing'(Fig.22) is a successive case.There are many Chinese traditional elements,such as metal and stone seals, Chinese character,Chinese Calligraphy,pen and ink ,in this logo,making the design be full of Chinese characteristics.Moreover,even if foreigners cannot understand the Chinese character in this logo,they still can guess that this logo concerns sports as they can see the dancing person.We can feel the attractiveness of Chinese traditional elements from this work.

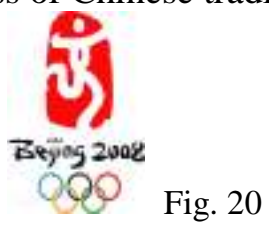




\section{Concluding Remarks}

The Chinese traditional element is an important part in Chinese art.Through the innovation and sedimentation, China is rich in cultural resources.Designers need to consider how they can give a new life to this element.Yanzu Li said: "national art and tradition are the origin to the modern art and modern design.To develop Chinese modern design, on the one hand, it needs the support from the modern scientific technology,and needs to learn advanced design experiences and methods; on the other hand,it needs to build upon our national art tradition.In a certain sense,national character belongs to both the world and our time."

Against the background of economic globalization,cultural globalization has swept all of the world.It is very important to deal with the relationship between Chinese culture and western culture.Just as the Japanese designer Kawara Yasuhira suggested,nationalization of graphic design is a useful way to protect nationalization.It is an important responsibility for Chinese designers to bring Chinese culture and Chinese design to the world.Chinese designers still have a long way to go.

\section{References}

[1] [X.Zhang,"Chinese traditional graphic art and modern logo design,”Journal of Central South University,Vol.13 No.5,pp.593-597,Oct.2007

[2] [H.Li,C.Liao, "Application of Chinese elements in modern graphic design,"Journal of Hubei University of Technology,Vol.24 No.3,pp.66-67,Jun. 2009

[3] M.Zhang,"Application of Chinese characters in logo design and the aesthetic effect,"Journal of Taishan University, Vol.32 No.1,pp.83-86,Jan. 2010 